\title{
ХАРАКТЕРИСТИКА ТАМОЖЕННЫХ УСЛУГ, ОКАЗЫВАЕМЫХ В РАМКАХ ОБЕСПЕЧЕНИЯ ТАМОЖЕННЫМИ ОРГАНАМИ ПРАВ ИНТЕЛЛЕКТУАЛЬНОЙ СОБСТВЕННОСТИ
}

\begin{abstract}
Аннотация: В статье дается характеристика таможенных услуг, оказываемых таможенными органами в рамках реализации функции по защите прав на объекты интеллектуальной собственности. Разграничивая понятия "государственной функции» и «государственной услуги», автор выделяет систему таможенных услуг (общего и специального характера) при реализации таможенными органами функции по защите прав на объекты интеллектуальной собственности. К таким услугам относится информирование и консультирование таможенных органов, а также ведение таможенного реестра объектов интеллектуальной собственности ФТС России. Исполнение государственной функции по ведению таможенного реестра объектов интеллектуальной собственности включает в себя целый ряд административных процедур. Эфрфективное осуществление рассматриваемой функции таможенных органов по обеспечению защиты прав на объекты интеллектуальной собственности в пределах своей компетенции основано на совокупности оказываемых общих и специальных услуг для потребителей, в качестве которых выступают прежде всего правообладатели исключительных прав на объекты интеллектуальной собственности.

Ключевые слова: таможенные органы, таможенные услуги, функции таможенных органов, потребители таможенных услуг, таможенный реестр, информирование, консультирование, административный регламент, качество таможенных услуг, объект интеллектуальной собственности.
\end{abstract}

$\mathbf{T}$ аможенная служба Российской Федерации, являясь неотъемлемой частью системы государственного управления внешнеторговой деятельностью, одновременно выступает в роли одного из основных механизмов ее регулирования, сочетая функции фискального, правоприменительного и контролирующего органа, и в то же время содействует развитию внешнеэкономической деятельности. Это означает, что в современных условиях таможенная служба Российской Федерации как часть экономической системы государства наряду с выполнением традиционных функций государственного администрирования в области налогообложения внешней торговли все активнее выступает как социально-экономический институт, где таможенная деятельность проявляется как особая форма услуги ${ }^{1}$.

Согласно пункту 1 статьи 2 Федерального закона от 27.07.2010 № 210-Ф3 «Об организации предоставления государственных и муниципальных услуг» государственная услуга, предоставляемая федеральным органом исполнительной власти,

\footnotetext{
Распоряжение Правительства РФ от 28.12.2012 № 2575-р «О Стратегии развития таможенной службы Российской Федерации до 2020 года». Собрание законодательства Российской Федерации от 14 января 2013 г. № 2. Ст. 109.
}

органом государственного внебюджетного фонда, исполнительным органом государственной власти субъекта Российской Федерации, а также органом местного самоуправления при осуществлении отдельных государственных полномочий, переданных федеральными законами и законами субъектов Российской Федерации, - это деятельность по реализации функций соответственно федерального органа исполнительной власти, государственного внебюджетного фонда, исполнительного органа государственной власти субъекта Российской Федерации, а также органа местного самоуправления при осуществлении отдельных государственных полномочий, переданных федеральными законами и законами субъектов Российской Федерации (далее - органы, предоставляющие государственные услуги), которая осуществляется по запросам заявителей в пределах установленных нормативными правовыми актами Российской Федерации и нормативными правовыми актами субъектов Российской Федерации полномочий органов, предоставляющих государственные услуги ${ }^{2}$.

Федеральный закон от 27.07.2010 N 210-Ф3 (ред. от 23.07.2013) «Об организации предоставления государственных и муниципальных услуг». Электронный ресурс. СПС «КонсультантПлюс». 
Современное таможенное законодательство Таможенного союза (далее - ТС) и России не содержит понятия «государственные услуги в области таможенного дела», а также понятия «государственные таможенные услуги».

Вместе с тем Регламент Федеральной таможенной службы, утвержденный приказом ФТС России от 26.12.2012 № 2656, закрепляет положение о том, что ФТС России в порядке и сроки, устанавливаемые Правительством РФ, осуществляет разработку административных регламентов исполнения государственных функций и предоставления государственных услуг, которые определяют административные процедуры, обеспечивающие осуществление функций ФТС России, эффективную работу главных управлений (управлений) ФТС России и должностных лиц, реализацию прав граждан. Предоставление государственных услуг осуществляется на основе административных регламентов предоставления государственных услуг, устанавливающих необходимый уровень их качества и доступности. ${ }^{3}$. В настоящее время перечень данных услуг отсутствует, а ученые дискутируют о видах и признаках услуг, оказываемых сегодня таможенными органами ${ }^{4}$.

Что касается потребителя государственных таможенных услуг, то специалисты выделяют в их качестве не только участников внешнеэкономической деятельности (ВЭД), но и само государство 5 .

По мнению В.В. Макрусева, государственная таможенная услуга (в широком контексте) - это общественно-экономическое благо в форме таможенной деятельности. В более узком контексте государственная таможенная услуга - это действия или последовательность действий, реализуемые специальными таможенными инструментами (включая таможенные процедуры, технологии, операции и т.п.) с целью повышения потребитель-

\footnotetext{
3 Приказ ФТС России от 26.12.2012 № 2656 «Об утверждении Регламента Федеральной таможенной службы» (Зарегистрировано в Минюсте России 26.03.2013 N 27888). Электронный ресурс. СПС «Гарант».

4 Трунина, Е. В. Государственные услуги таможенных органов: признаки, виды, проблемы определения / Е. В. Трунина // Современное право . - 2009. - № 8. - С. 71.

5 Основы таможенного дела: учебник / под общ. ред. А.Я. Черныша, д-ра воен. наук, проф. М.: Изд-во Российской таможенной академии, 2012. - С. 315; Симахин О.Г. Теоретическое обоснование структуры и порядка функционирования инновационной системы управления государственными таможенными услугами / Вестник Российской таможенной академии. 2011. № 4. - С. 29.
}

ской полезности сферы ВЭД для государства и участников внешнеторговой деятельности ${ }^{6}$.

Поскольку деятельность таможенных органов можно рассматривать в том числе и как услуговую (деятельность по предоставлению услуг), то в конечном итоге объем, качество и эффективность предоставляемой ГТУ (государственной таможенной услуги) определяется именно структурой и организацией ее производства. Однако для участника ВЭД структура, строение системы управления ГТУ могут быть вторичными. Наиболее значимо для него не то, как организован процесс обслуживания, а, прежде всего, то, что получает он в результате обслуживания ${ }^{7}$.

Следует согласиться с Е.В. Труниной, которая называет в качестве признаков, характеризующих государственную услугу в сфере таможенного дела, следующие: добровольность обращения лиц в таможенные органы, если оно не связано с исполнением требований таможенного законодательства, и получение определенных благ в сфере таможенного дела исключительно в интересах обратившегося лица ${ }^{8}$. Обратим внимание на то, что данные признаки относятся к государственным услугам в сфере таможенного дела, предназначенным для потребителя - участника ВЭД.

ФТС России в настоящее время оказывает целый ряд государственных услуг заинтересованным лицам. Одним из факторов достижения стратегической цели таможенной службы Российской Федерации в части содействия международной торговле является качественное предоставление государственных услуг в области таможенного дела участникам внешнеэкономической деятельности. В таможенных органах такая деятельность осуществляется безвозмездно в рамках соответствующих административных регламентов.

Таможенная служба Российской Федерации предоставляет государственные услуги, опираясь на мировой опыт в области взаимодействия с бизнес-сообществом. На сегодняшний день в тамо-

\footnotetext{
6 Макрусев В.В. Государственные таможенные услуги: монография / В.В. Макрусев, А.В. Сафронов. - 2-е изд. - М.: Изд-во Российской таможенной академии, 2011. - С. 27.

Симахин О.Г. Теоретическое обоснование структуры и порядка функционирования инновационной системы управления государственными таможенными услугами / Вестник Российской таможенной академии. 2011. № 4. - С. 29.

8 Трунина, Е. В. Государственные услуги таможенных органов: признаки, виды, проблемы определения / Е. В. Трунина // Современное право . - 2009. — № 8. - С. 72.
} 
женных органах применяется 15 административных регламентов по исполнению государственных функций (предоставлению государственных услуг).

Эффективные и качественные государственные услуги в области таможенного дела содействуют увеличению скорости таможенных процессов, снижают издержки предпринимателей и конечного потребителя товара, позволяют повысить безопасность в сфере внешнеэкономической деятельности, что способствует развитию бизнеса и торговой деятельности на территории Единого экономического пространства9.

Рассмотрим виды государственных таможенных услуг при реализации таможенными органами функции по защите прав интеллектуальной собственности. Здесь следует выделить две группы услуг: общего характера и специальные.

Услуги общего характера являются универсальными и традиционными для всех направлений деятельности таможенных органов РФ. Среди них следует назвать услуги по информированию об актах таможенного законодательства Таможенного союза, законодательства Российской Федерации о таможенном деле и об иных правовых актах Российской Федерации в области таможенного дела и консультированию по вопросам таможенного дела и иным вопросам, входящим в компетенцию таможенных органов. Порядок предоставления данных услуг определен Административным регламентом ФТС России по предоставлению государственной услуги по информированию об актах таможенного законодательства Таможенного союза, законодательства Российской Федерации о таможенном деле и об иных правовых актах Российской Федерации в области таможенного дела и консультированию по вопросам таможенного дела и иным вопросам, входящим в компетенцию таможенных органов ${ }^{10}$.

9 Распоряжение Правительства РФ от 28.12.2012 № 2575-р «О Стратегии развития таможенной службы Российской Федерации до 2020 года». Собрание законодательства Российской Федерации от 14 января 2013 г. № 2. Ст. 109.

10 Приказ ФТС России от 09.06.2012 N 1128 “Об утверждении Административного регламента Федеральной таможенной службы по предоставлению государственной услуги по информированию об актах таможенного законодательства Таможенного союза, законодательства Российской Федерации о таможенном деле и об иных правовых актах Российской Федерации в области таможенного дела и консультированию по вопросам таможенного дела и иным вопросам, входящим в компетенцию таможенных органов" (Зарегистрировано в Минюсте России 10.07.2012 N 24873) // "Российская газета", № 174, 01.08.2012.
Согласно данному документу консультирование по вопросам таможенного дела и иным вопросам, входящим в компетенцию таможенных органов, предоставляется по конкретным таможенным правоотношениям, касающимся:

- $\quad$ совершения таможенных операций и проведения таможенного контроля товаров и транспортных средств;

- включения юридических лиц в реестры лиц, осуществляющих деятельность в области таможенного дела;

- таможенного транзита;

- $\quad$ временного хранения товаров;

- $\quad$ применения таможенных процедур;

- $\quad$ порядка таможенного декларирования товаров и транспортных средств, представления документов при таможенном декларировании товаров и транспортных средств, выпуска товаров;

- перемещения товаров физическими лицами для личных, семейных, домашних и иных не связанных с осуществлением предпринимательской деятельности нужд;

- перемещения товаров в международных почтовых отправлениях;

- $\quad$ перемещения товаров трубопроводным транспортом и по линиям электропередачи;

- иных вопросов, входящих в компетенцию таможенных органов.

Таким образом, в рамках рассматриваемой нами функции таможенных органов по обеспечению прав интеллектуальной собственности консультирование может предоставляться по вопросам в области таможенных правоотношений, касающихся:

- $\quad$ совершения таможенных операций и проведения таможенного контроля товаров и транспортных средств, содержащих объекты интеллектуальной собственности;

- применения таможенных процедур в отношении товаров, содержащих объекты интеллектуальной собственности;

- порядка таможенного декларирования товаров и транспортных средств, содержащих объекты интеллектуальной собственности;

- представления документов при таможенном декларировании товаров и транспортных средств, содержащих объекты интеллектуальной собственности;

- выпуска товаров, содержащих объекты интеллектуальной собственности, и др.

Государственные услуги по информированию об актах таможенного законодательства Таможен- 
ного союза, законодательства Российской Федерации о таможенном деле и об иных правовых актах Российской Федерации в области таможенного дела и консультированию по вопросам таможенного дела и иным вопросам, входящим в компетенцию таможенных органов, осуществляются как в устной, так и письменной форме.

Специальные таможенные услуги при осуществлении таможенного контроля в отношении товаров, содержащих объекты интеллектуальной собственности, включают в себя, прежде всего, услуги по ведению таможенного реестра объектов интеллектуальной собственности (далее - ТРОИС, Реестр) ФТС России, а также опубликование данных ТРОИС ФТС России в официальных электронных и печатных изданиях Федеральной таможенной службы.

Рассмотрим услугу по ведению ТРОИС ФТС России более подробно.

Ведение таможенного реестра объектов интеллектуальной собственности первоначально носило информационный характер. Государственный таможенный комитет РФ (ГТК России) еще в конце 90-х годов прошлого века вел определенные списки объектов интеллектуальной собственности, правообладатели которых обращались в таможенные органы с просьбой о принятии мер защиты в связи с трансграничным перемещением товаров, содержащих объекты интеллектуальной собственности. Одним из таких обращений было письмо ОАО «Кондитерский концерн Бабаевский», которое содержало требование запрещать ввоз, использование и иное введение в хозяйственный оборот обозначенной товарным знаком концерна кондитерской продукции других предприятий. На основании данного обращения ГТК России включил ряд товарных знаков в реестр объектов интеллектуальной собственности ${ }^{11}$. Следует отметить, что услуга по ведению ТРОИС сформировалась по инициативе самих правообладателей. Лишь позже она была законодательно и организационно оформлена в Таможенном кодексе РФ 2003 года.

В настоящее время процедура включения объектов интеллектуальной собственности в ТРОИС ФТС России закреплена в Административном регламенте Федеральной таможенной службы по исполнению государственной функции по ведению таможенного реестра объектов интеллектуальной собственности (далее - Административный ре-

11 Обращение ОАО «Кондитерский концерн Бабаевский» о товарных знаках. гламент), который определяет сроки и последовательность действий (административных процедур) ФТС России, порядок взаимодействия ФТС России, ее структурных подразделений, региональных таможенных управлений, таможен между собой, а также с правообладателями (их представителями), федеральными органами исполнительной власти, правоохранительными органами, органами прокуратуры, судебными органами, органами исполнительной власти субъектов РФ, органами местного самоуправления и иными государственными органами РФ и государственными органами субъектов РФ, к компетенции которых отнесены вопросы, связанные с охраной и защитой прав интеллектуальной собственности, банками, иными кредитными и страховыми организациями, участниками внешнеэкономической деятельности и иными лицами, деятельность которых связана с осуществлением внешнеэкономической деятельности, а также с иными учреждениями, организациями и гражданами при исполнении государственной функции по ведению таможенного реестра объектов интеллектуальной собственности ${ }^{12}$.

Заметим, что в соответствии с данным Административным регламентом ведение ТРОИС ФТС России представлено в качестве государственной функции, а не государственной услуги.

При этом согласно части 1 статьи 12 Федерального закона «0 таможенном регулировании в РФ» таможенные органы выполняют целый ряд функций (обязанностей), в том числе:

- обеспечивают в пределах своей компетенции защиту прав на объекты интеллектуальной собственности;

- осуществляют информирование и консультирование в области таможенного дела, обеспечивают в установленном порядке государственные органы, организации и граждан информацией по вопросам таможенного дела ${ }^{13}$.

Таким образом, обеспечение в пределах своей компетенции защиты прав на объекты интеллектуальной собственности является одной из основных функций таможенных органов РФ. Ведение

\footnotetext{
12 Приказ ФТС РФ от 13.08.2009 № 1488 «Об утверждении Административного регламента Федеральной таможенной службы по исполнению государственной функции по ведению таможенного реестра объектов интеллектуальной собственности» (Зарегистрировано в Минюсте РФ 14.12.2009 № 15592). Электронный ресурс. СПС «Гарант».

13 Федеральный закон Российской Федерации от 27 ноября 2010 г. № 311-Ф3 «О таможенном регулировании в Российской Федерации» // Российская газета. 29 ноября 2010 года.
} 
ТРОИС ФТС России также называется законодателем государственной функцией, которая, на наш взгляд, носит более конкретный характер и детализирует основную функцию по защите прав на объекты интеллектуальной собственности. В то же время ведение ТРОИС ФТС России относится нами к таможенным услугам по принципу того, что его реализация осуществляется в соответствии с разработанным порядком (регламентом).

Такое параллельное применение в законодательстве терминов «функции» и «услуги» свидетельствует о значительной близости рассматриваемых понятий. При этом, на наш взгляд, следует исключить мнение о тождественности понятий «функции» и «услуги» применительно к таможенной и иной административной деятельности. В этой связи следует согласиться с позицией современных ученых, заключающейся в том, что под функцией понимается «нормативно установленный вид властной деятельности органа государства», а под услугой - «способ удовлетворения потребностей граждан и юридических лиц». Реализация функции не исключает оказания услуги, так как таможенная услуга - это услуга, обладающая своими особенностями и имеющая двойственный характер, т.е., с одной стороны, связана с реализацией возложенных на таможенные органы функций, а с другой - имеет целью удовлетворение нужд потребителей услуги. Так, реализации функции имеет результатом оказанную услугу ${ }^{14}$.

Таким образом, эффективное осуществление рассматриваемой нами функции таможенных органов по обеспечению защиты прав на объекты интеллектуальной собственности в пределах своей компетенции основано на совокупности оказанных специальных услуг для правообладателей, а именно: включении их объектов интеллектуальной собственности в ТРОИС ФТС России.

Исполнение государственной функции по ведению таможенного реестра объектов интеллектуальной собственности включает в себя следующие административные процедуры:

- принятие и рассмотрение заявления о принятии мер, связанных с приостановлением выпуска товаров;

- внесение объектов интеллектуальной собственности в ТРОИС ФТС России на основании заявлений правообладателей (их представителей);

14 Основы таможенного дела: учебник / под общ. ред. А.Я. Черныша, д-ра воен. наук, проф. М.: Изд-во Российской таможенной академии, 2012. - С. 314-315.
- исключение объектов интеллектуальной собственности из ТРОИС ФТС России;

- $\quad$ внесение в ТРОИС ФТС России изменений и дополнений;

- $\quad$ опубликование перечня объектов интеллектуальной собственности, внесенных в ТРОИС ФТС России, доведение данных ТРОИС ФТС России до сведения таможенных органов и заинтересованных лиц;

- взаимодействие таможенных органов с государственными органами, гражданами и организациями по вопросам, связанным с ведением ТРОИС ФТС России ${ }^{15}$.

Говоря о конкретных потребителях рассматриваемых нами услуг общего и специального характера, отметим, что потребителями первой группы услуг (общего характера) потенциально являются все участники ВЭД, любое заинтересованное лицо.

Специальная услуга по внесению объекта интеллектуальной собственности в ТРОИС ФТС России предназначена только для правообладателей. При этом согласно части 2 статьи 305 Федерального закона «О таможенном регулировании в РФ» меры по защите прав на объекты интеллектуальной собственности принимаются в отношении товаров, содержащих объекты авторского права и смежных прав, товарные знаки, знаки обслуживания и наименования мест происхождения товара, включенные по заявлению правообладателя в таможенный реестр объектов интеллектуальной собственности ${ }^{16}$.

Таким образом, потребителями услуги по включению объекта интеллектуальной собственности в ТРОИС ФТС России могут быть следующие категории правообладателей: авторы, владельцы смежных прав, обладатели исключительных прав на товарные знаки, знаки обслуживания и наименования мест происхождения товаров.

При ведении Реестра ФТС России руководствуется принципами защиты государством прав интеллектуальной собственности, прав и законных интересов российских производителей и потребителей, гласности, равнодоступности для всех обладателей исключительных прав на объекты автор-

15 Приказ ФТС РФ от 13.08.2009 № 1488 «Об утверждении Административного регламента Федеральной таможенной службы по исполнению государственной функции по ведению таможенного реестра объектов интеллектуальной собственности» (Зарегистрировано в Минюсте РФ 14.12.2009 № 15592). Электронный ресурс. СПС «Гарант».

16 Федеральный закон Российской Федерации от 27 ноября 2010 г. № 311-Ф3 «О таможенном регулировании в Российской Федерации» // Российская газета. 29 ноября 2010 года. 
ского права и смежных прав, на товарные знаки, знаки обслуживания и обладателей исключительного права использования наименования места происхождения товара, недопустимости причинения вреда третьим лицам, недопущения необоснованного увеличения сроков и неоправданных задержек исполнения государственной функции ${ }^{17}$.

Заслуживает внимания тот факт, что осуществление различных услуг в рамках реализации функции по обеспечению защиты прав на объекты интеллектуальной собственности таможенными органами неразрывно связано друг с другом. Так, согласно п. 5 Административного регламента Федеральной таможенной службы по исполнению государственной функции по ведению таможенного реестра объектов интеллектуальной собственности ФТС России обеспечивает:

- доведение данных Реестра до сведения таможенных органов и обладателей исключительных прав на объекты авторского права и смежных прав, на товарные знаки, знаки обслуживания и обладателей исключительного права использования наименования места происхождения товара (их представителей);

- представление заинтересованным государственным органам, гражданам и организациям выписок из Реестра;

- опубликование перечня объектов интеллектуальной собственности, внесенных в Реестр, в своих изданиях: Бюллетене таможенной информации «Таможенные ведомости», информационно-аналитическом обозрении «Таможня»;

- информирование, в том числе с использованием информационных технологий, о подготавливаемых правовых актах, а также о не вступивших в силу изменениях и дополнениях в правовые акты, затрагивающие вопросы, связанные с ведением Реестра ${ }^{18}$.

Таким образом, можно сделать вывод о том, что в рамках реализации функции таможенных

17 Приказ ФТС РФ от 13.08.2009 № 1488 «Об утверждении Административного регламента Федеральной таможенной службы по исполнению государственной функции по ведению таможенного реестра объектов интеллектуальной собственности» (Зарегистрировано в Минюсте РФ 14.12.2009 № 15592). Электронный ресурс. СПС «Гарант».

18 Приказ ФТС РФ от 13.08.2009 № 1488 «Об утверждении Административного регламента Федеральной таможенной службы по исполнению государственной функции по ведению таможенного реестра объектов интеллектуальной собственности» (Зарегистрировано в Минюсте РФ 14.12.2009 № 15592). Электронный ресурс. СПС «Гарант». органов по обеспечению защиты прав на объекты интеллектуальной собственности ими оказываются государственные таможенные услуги (общего и специального характера) в комплексе. Осуществление государственной функции по ведению ТРОИС ФТС России таможенными органами сопровождается оказанием сопутствующих услуг универсального характера, таких как информирование об актах таможенного законодательства ТС и РФ, информирование о данных ТРОИС ФТС России и другие. Данные ТРОИС ФТС России находятся в открытом доступе на официальном сайте ФТС России и регулярно обновляются ${ }^{19}$.

Согласно Стратегии развития таможенной службы Российской Федерации до 2020 года в связи с прогнозируемым спросом на услуги в области таможенного дела предполагается совершенствовать предоставление государственных услуг путем решения следующих задач:

- повышение качества и доступности государственных услуг в области таможенного дела;

- интеграция единой автоматизированной информационной системы таможенных органов в существующую инфраструктуру предоставления услуг и функций в электронном виде в целях обеспечения доступности и повышения качества предоставления государственных услуг в области таможенного дела;

- $\quad$ разработка системы показателей, методического обеспечения и системы мониторинга качества предоставления государственных услуг в области таможенного дела.

В качестве целевых индикаторов указанного направления развития таможенной службы Российской Федерации представлены:

- доля участников внешнеэкономической деятельности, удовлетворительно оценивающих качество предоставления государственных услуг таможенными органами, в общем количестве опрошенных (с 30 процентов в 2012 году до 70 процентов к 2020 году);

- $\quad$ доля государственных услуг, предоставляемых Федеральной таможенной службой в электронном виде в соответствии с административными регламентами, по которым обеспече-

19 Таможенный реестр объектов интеллектуальной собственности (по состоянию на 04.10.2013 года) / Электронный peсурс. Официальный сайт ФТСРоссии. http://ved.customs.ru/ index.php?option $=$ com_content\&view $=$ article\&id $=109: 2010$ 09-09-06-26-44\&catid=13:2008-10-16-13-5115\&Itemid=1814. Дата обр. 13.10.2013. 
на возможность их получения в электронном виде, в общем объеме государственных услуг, предоставляемых Федеральной таможенной службой (с 1 процента в 2012 году до 100 процентов к 2014 году) ${ }^{20}$.

Что касается перспектив развития и оптимизации специальной услуги таможенных органов, связанной с ведением ТРОИС ФТС России, то в данном случае нами выделены следующие направления:

- $\quad$ возможность внесения правообладателем объекта интеллектуальной собственности в ТРОИС ФТС России в электронном виде (с использованием официального сайта ФТС России);

- отмена необходимости предоставления правообладателем обязательства о возмещении имущественного вреда или договора страхования риска ответственности (согласно части 2 статьи 307 Федерального закона «0 таможенном регулировании в РФ» сумма обеспечения обязательства или страховая сумма должна быть не менее 300000 рублей);

- создание единой информационной базы ФТС России и Федеральной службы по интеллектуальной собственности (Роспатент), которая позволит обеспечить автоматическую актуализацию данных ТРОИС ФТС России с соответствующими базами данных Роспатента.
В заключение отметим, что несмотря на внедрение принципа «ех officio» на территории Таможенного союза (в рамках которого таможенные органы вправе приостанавливать выпуск товаров, содержащих объекты интеллектуальной собственности, не внесенные в Реестр, при обнаружении признаков нарушения прав интеллектуальной собственности и при наличии информации о правообладателе (его представителе) на территории РФ), ТРОИС ФТС России продолжает оставаться основой административного механизма защиты прав на объекты интеллектуальной собственности таможенными органами в условиях формирования Евразийского экономического пространства. И от того, насколько качественно будут осуществляться таможенные услуги по ведению ТРОИС ФТС России, насколько будут удовлетворены правообладатели как основные потребители данной услуги таможенных органов, насколько эффективно будет организовано информирование и консультирование таможенными органами по вопросам защиты прав на объекты интеллектуальной собственности, будет зависеть реализация одной из важнейших функций (обязанностей) таможенных органов в современный период - обеспечение в пределах своей компетенции защиты прав на объекты интеллектуальной собственности.

\section{Библиография:}

1. Макрусев В.В. Государственные таможенные услуги: монография / В.В. Макрусев, А.В. Сафронов. - 2-е изд. - М.: Изд-во Российской таможенной академии, 2011.

2. Обращение URL: OAO «Кондитерский концерн Бабаевский» о товарных знаках. http://www.babaev.ru/ about/pressa13.html (дата обращения: 25.07.2013).

3. Основы таможенного дела: учебник / под общ. ред. А.Я. Черныша, д-ра воен. наук, проф. М.: Изд-во Российской таможенной академии, 2012.

4. Приказ ФТС России от 09.06.2012 N 1128 «Об утверждении Административного регламента Федеральной таможенной службы по предоставлению государственной услуги по информированию об актах таможенного законодательства Таможенного союза, законодательства Российской Федерации о таможенном деле и об иных правовых актах Российской Федерации в области таможенного дела и консультированию по вопросам таможенного дела и иным вопросам, входящим в компетенцию таможенных органов» (Зарегистрировано в Минюсте России 10.07.2012 N 24873) // «Российская газета», № 174, 01.08.2012.

5. Приказ ФТС РФ от 13.08.2009 № 1488 «Об утверждении Административного регламента Федеральной таможенной службы по исполнению государственной функции по ведению таможенного реестра объектов интеллектуальной собственности» (Зарегистрировано в Минюсте РФ 14.12.2009 № 15592). Электронный ресурс. СПС «Гарант».

20 Распоряжение Правительства РФ от 28.12.2012 № 2575-р «О Стратегии развития таможенной службы Российской Федерации до 2020 года». Собрание законодательства Российской Федерации от 14 января 2013 г. № 2. Ст. 109. 
Административное и муниципальное право 2 (74) • 2014

6. Приказ ФТС России от 26.12.2012 № 2656 «Об утверждении Регламента Федеральной таможенной службы» (Зарегистрировано в Минюсте России 26.03.2013 N 27888). Электронный ресурс. СПС «Гарант».

7. Распоряжение Правительства РФ от 28.12.2012 № 2575-р «О Стратегии развития таможенной службы Российской Федерации до 2020 года». Собрание законодательства Российской Федерации от 14 января 2013 г. № 2. Ст. 109.

8. Симахин О.Г. Теоретическое обоснование структуры и порядка функционирования инновационной системы управления государственными таможенными услугами / Вестник Российской таможенной академии. 2011. № 4.

9. Таможенный реестр объектов интеллектуальной собственности (по состоянию на 04.10.2013 года) / Электронный ресурс. Официальный сайт ФТС России. http://ved.customs.ru/index.php?option=com_ content\&view=article\&id=109:2010-09-09-06-26-44\&catid=13:2008-10-16-13-51-15\&Itemid=1814. Дата обр. 13.10.2013.

10. Трунина, Е. В. Государственные услуги таможенных органов: признаки, виды, проблемы определения / Е. В. Трунина // Современное право --2009.-№ 8.

11. Федеральный закон от 27.07.2010 N 210-ФЗ (ред. от 23.07.2013) «Об организации предоставления государственных и муниципальных услуг». Электронный ресурс. СПС «КонсультантПлюс».

12. Федеральный закон Российской Федерации от 27 ноября 2010 г. № 311-Ф3 «0 таможенном регулировании в Российской Федерации» // Российская газета. 29 ноября 2010 года.

\section{References (transliterated):}

1. Makrusev V.V. Gosudarstvennye tamozhennye uslugi: monografiya / V.V. Makrusev, A.V. Safronov. — 2-e izd. — M.: Izd-vo Rossiiskoi tamozhennoi akademii, 2011.

2. Obrashchenie URL:OOAO «Konditerskii kontsern Babaevskii» o tovarnykh znakakh. http://www.babaev.ru/ about/pressa13.html (data obrashcheniya: 25.07.2013).

3. Osnovy tamozhennogo dela: uchebnik / pod obshch. red. A.Ya. Chernysha, d-ra voen. nauk, prof. M.: Izd-vo Rossiiskoi tamozhennoi akademii, 2012.

4. Prikaz FTS Rossii ot 09.06.2012 N 1128 «Ob utverzhdenii Administrativnogo reglamenta Federal'noi tamozhennoi sluzhby po predostavleniyu gosudarstvennoi uslugi po informirovaniyu ob aktakh tamozhennogo zakonodatel'stva Tamozhennogo soyuza, zakonodatel'stva Rossiiskoi Federatsii o tamozhennom dele i ob inykh pravovykh aktakh Rossiiskoi Federatsii v oblasti tamozhennogo dela i konsul'tirovaniyu po voprosam tamozhennogo dela i inym voprosam, vkhodyashchim v kompetentsiyu tamozhennykh organov» (Zaregistrirovano v Minyuste Rossii 10.07.2012 N 24873) // «Rossiiskaya gazeta», № 174, 01.08.2012.

5. Prikaz FTS RF ot 13.08.2009 № 1488 «Ob utverzhdenii Administrativnogo reglamenta Federal'noi tamozhennoi sluzhby po ispolneniyu gosudarstvennoi funktsii po vedeniyu tamozhennogo reestra ob"ektov intellektual'noi sobstvennosti» (Zaregistrirovano v Minyuste RF 14.12.2009 № 15592). Elektronnyi resurs. SPS «Garant».

6. Prikaz FTS Rossii ot 26.12.2012 № 2656 «Ob utverzhdenii Reglamenta Federal'noi tamozhennoi sluzhby» (Zaregistrirovano v Minyuste Rossii 26.03.2013 N 27888). Elektronnyi resurs. SPS «Garant».

7. Rasporyazhenie Pravitel’stva RF ot 28.12.2012 № 2575-r «0 Strategii razvitiya tamozhennoi sluzhby Rossiiskoi Federatsii do 2020 goda». Sobranie zakonodatel’stva Rossiiskoi Federatsii ot 14 yanvarya 2013 g. № 2. St. 109.

8. Simakhin O.G. Teoreticheskoe obosnovanie struktury i poryadka funktsionirovaniya innovatsionnoi sistemy upravleniya gosudarstvennymi tamozhennymi uslugami / Vestnik Rossiiskoi tamozhennoi akademii. 2011. № 4.

9. Tamozhennyi reestr ob"ektov intellektual'noi sobstvennosti (po sostoyaniyu na 04.10.2013 goda) / Elektronnyi resurs. Ofitsial'nyi sait FTS Rossii. http://ved.customs.ru/index.php?option=com_content\&view=article \&id=109:2010-09-09-06-26-44\&catid=13:2008-10-16-13-51-15\&Itemid=1814. Data obr. 13.10.2013.

10. Trunina, E. V. Gosudarstvennye uslugi tamozhennykh organov: priznaki, vidy, problemy opredeleniya / E. V. Trunina // Sovremennoe pravo .-2009.-№ 8.

11. Federal'nyi zakon ot 27.07.2010 N 210-FZ (red. ot 23.07.2013) «Ob organizatsii predostavleniya gosudarstvennykh i munitsipal'nykh uslug». Elektronnyi resurs. SPS «Konsul'tantPlyus».

12. Federal'nyi zakon Rossiiskoi Federatsii ot 27 noyabrya 2010 g. № $311-\mathrm{FZ}$ «O tamozhennom regulirovanii v Rossiiskoi Federatsii» // Rossiiskaya gazeta. 29 noyabrya 2010 goda. 